\title{
Delegated Causality of Complex Systems
}

\author{
Raimundas Vidunas $^{1}$ (D)
}

Received: 16 November 2017 / Accepted: 16 February 2018 / Published online: 22 May 2018 (C) The Author(s) 2018

\begin{abstract}
A notion of delegated causality is introduced here. This subtle kind of causality is dual to interventional causality. Delegated causality elucidates the causal role of dynamical systems at the "edge of chaos", explicates evident cases of downward causation, and relates emergent phenomena to Gödel's incompleteness theorem. Apparently rich implications are noticed in biology and Chinese philosophy. The perspective of delegated causality supports cognitive interpretations of selforganization and evolution.
\end{abstract}

Keywords Causality $\cdot$ Emergence $\cdot$ Reductionism $\cdot$ Self-organization $\cdot$ Yin and Yang

\section{Introduction}

Living organisms, ecosystems, human minds, societies, economic markets are widely recognized as extraordinary complex systems. They are impressively organized and possess properties that are hardly reducible to qualities of physical matter. Thereby they seem to contradict the reductionistic paradigm of fundamental causation from underlying physical processes. As yet, satisfying explanation of emerging coherent organization is a comparable challenge for reductionist and holistic philosophies (Capra and Luisi 2014; Heylighen et al. 2007). Even if the reductionist approach continues to deliver outstanding results in physics, chemistry, molecular biology, neuropsychology, much deeper understanding of living (Schrödinger 1944;

Raimundas Vidunas

rvidunas@gmail.com

1 Max Planck Institute for Mathematics, Vivatsgasse 7, 53111 Bonn, Germany 
Murphy and O’Neil 1995) and conscious (Kim 1998; Varela et al. 1991) agencies may require an uneasy paradigm change, after all.

I introduce a concept that can simplify and unify analysis of intricate causal relations in complex systems to a remarkable extent. This concept of delegated causality should clarify much about emergence of whole new phenomena (Clayton and Davies 2006), spontaneous order (Kauffman 1993), synergy (Corning 2005), functionality (Ariew et al. 2002), purpose and intention (Dennett 1987). If the new conception indeed refines established specialist perspectives, it will be worth revisiting sporadic revivals of Emergentism (Clayton and Davies 2006, pp. 9-26), post-Enlightenment rationalist skepticism (Clayton and Davies 2006, pp. 114), classical Greek teleologies (Ariew et al. 2002, pp. 7-30). The most rigorous contemporary relevance of the new perspective is to physics of emergence (Mainwood 2006), symmetry breaking (Anderson 1972; Moon and LaRock 2017), thermodynamics (Prigogine and Nicolis 1977; England 2013), and to information-theoretic measure of causal influence (Hoel 2017; Tononi and Sporns 2003).

A comprehensive overview of the vast, growing literature on complex systems, self-organization, emergence would not serve the purpose of this article to introduce delegated causality. This simple but subtle, overlooked kind of causality is anticipated or provoked (figuratively speaking) by critical dynamical systems with rich behavior and moderate sensitivity to the environment. The scope of my abstracted terminology will become clear with the introduction of methodology $[M 1]-[M 3]$ in Sect. 3 of analyzing causal interactions. Evident implications of delegated causality will be demonstrated by a brief account of evolutionary biology (in Sect. 5) and a reference to Chinese philosophy (in Sect. 6).

This spirited article would be presentable to a scientific version of the TV show “The X-Factor" (Hackley et al. 2012). My argumentation is not deep formally, as the chief purpose is to justify the new concept by a few evocative arguments, agreeable examples, and links to existing ideas. This manner of aboutness (Yablo 2014) mirrors the general view of self-organization conveyed here. I start by reassessing contemporary modeling of complex systems in Sect. 2. The fresh kind of causality is introduced formally in Sect. 3. Section 4 examines physical reductionism in the new light, and relates emergence, downward causation to Gödel's (1931) incompleteness theorem. The later sections deliberate a few compelling (though not entirely comfortable) implications. All together, this article is gradually making a holistic argument for a new comprehensive view by building up the context for the integrating Sect. 7.

\section{Complex Systems}

Natural complex systems are studied under many frameworks: self-organization (Ashby 1962; Depew and Weber 1999), complex adaptive systems (Miller and Page 2007; Horgan 1995), autopoiesis (Maturana and Varela 1980), dissipative structures (Prigogine and Nicolis 1977), self-organized criticality (Bak 1996; Watkins et al. 2015), etc. The models are often based on non-linear dynamical systems, their attractors, non-equilibrium thermodynamics (England 2013; Kondepudi et al. 
2015), phase transitions (Brochini et al. 2016), scaling analysis (West 2017), cellular automata (Wolfram 2002; Langton 1990), variation and selection mechanisms (Heylighen 2000; Vijver et al. 1998), systems theory (von Bertalanffy 1968; Capra and Luisi 2014), developmental frameworks (Salthe 1993; Coffman 2011), information dynamics (Lerner 2007). Phenomenology at the center of attention includes spontaneous increase of order (Holland 1995; Kauffman 1993), emergence of coherent global behaviors from local interactions (Popkin 2016), adaptation to environment perturbations. de Wolf and Holvoet (2005) put forward applicable distinction between self-organization and emergence.

Autonomy, decentralized control, interactive closure are often among defining features of complex systems (Maturana and Varela 1980; Moreno and Mossio 2015). But the autonomy assumption should not be idealized, especially when considering causation in actual complex phenomena. Reflections in this article suggest that behaviors (of constituting agents or the whole system) which amount to control sharing or transfer can be very far reaching.

It will help clarity here to contrast various complex systems on the two-dimensional spectrum that combines interactivity with the environment and homogeneity of constituents; see Fig. 1. Living organisms are highly non-homogeneous and experience variable pressure (often self-inflicted) from the environment. Their biological and physical organization is nested hierarchical (Salthe 2012):

[ organism [ organs [ tissues [ cells [ biomolecules [atoms [ ... ]]]]]]];

and they live in similarly nested hierarchical environments:

[ [ [ [ [ [ organisms ] flocks ] habitats ] ecosystems ] biosphere ] planet ] ... ].

General heterogeneous adaptive systems are mainly organized in a hierarchal way as outlined by Simon (1962). Intense, diverse interactivity between levels facilitates growth and adaptation. Let $P$ denote the spectral corner representing these systems.

Let $Q$ denote the opposite spectral corner in Fig. 1. Do we find phase transitions of homogeneous matter there? Their unfolding depends on a few macro-parameters such as temperature, and the environment influences them once it is included in a model. Similarly, chaotic dynamical systems are highly sensitive to perturbations. Hence deviations from deterministic trajectories are inevitable once a bit of

Fig. 1 The two-dimensional spectrum of interactivity with the environment and homogeneity of complex systems

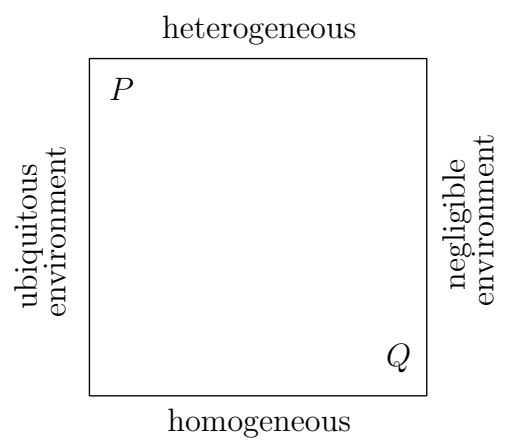


environment exists. Dynamics with a finite time singularity (Johansen and Sornette 2001) will inevitably change before the singularity. Exponentially growing dynamics are likely to meet boundary limitations as well.

Are there deep causal implications of this practically unavoidable environmental influence, particularly when the system happens to be fine-tuned to be influenced? Does this perceptive condition allow genuine downward causation from emergent entities? At least, can these queries be resolved for emergent phenomena near the corner $Q$, where reduction to basic physical causes seems to be assured? This article starts to address these questions.

Physical reduction is practically ineffectual near the corner $P$. The renowned biologist Mayr (2004, Ch. 4) writes : "the physiochemical approach is totally sterile in evolutionary biology", and "analysis is continued downward only as long as it yields useful new information”. Furthermore, Mayr cites Popper's (1974, pp. 269, 281) harsh critique: "as a philosophy, reductionism is a failure ... we live in a universe of emergent novelty; of a novelty which, as a rule, is not completely reducible to any of the preceding stages." If physical reductionism is tenable after all, it is extremely deeply masked near the corner $P$. I reckon that this masking is done by layers of delegated causality.

\section{Delegated Causation}

We affirm our focus by the following three definitions. They suggest a non-reductive perspective where the focus is on potential interactions between dynamical processes rather than mathematical behavior of a single dynamical model. The first definition characterizes those (continuous or discrete) dynamical systems or their equilibria, bifurcations, critical phases, "edge of chaos" conditions (Waldrop 1993; Kauffman 1993) that are "waiting to be perturbed", figuratively speaking.

Definition 1 A dynamical system (or its state) is primed if it can exhibit complex, potentially utilitarian behaviors depending on moderate adjustment of boundary conditions.

This definition may seem unsatisfactory because of several subjective terms. However, the hint of subjectivity and external references are important features of the definition. Primed dynamical systems are to be considered not in isolation but under influence from each other and the environment. They passively, reactively follow the laws of physics, boundary conditions, perturbations. Most dynamical systems can be considered as primed if potential interactions with other systems are sufficiently interesting. Definite examples of non-primed systems would be chaotic systems or those in a thermodynamic equilibrium.

Once feedback loops between intricate reactions and triggers of various primed systems materialize, an elaborate cybernetic or evolutionary system may come out. Let us use an economic metaphor for the full spectrum of relative, relational configurations of this kind. 
Definition 2 A broad market is a set of primed dynamical systems, triggering influences and potential reactions between them.

Extending the economic metaphor, we may refer to sensitivities of a primed dynamical system as its demand, and to the driving effect as supply. A broad market may be structured into hierarchical (Simon 1962; Salthe 2012) or cybernetic modules, or dominated by an exchange regime of that supply and demand.

Definition 3 The causal relation between a primed dynamical system and an external, emergent or self-organized influence that drives the dynamical system by a moderate force of interaction is called delegated causation.

The "moderate force" here is defined in the capability context of driving influences. Their dynamic realization is beside the main point. Just as operative features of supply are fairly unimportant in marketing and commerce, the causal relation is not defined by the substance of influence factors. I discuss possible dynamic nature of driving influences at the end of Sect. 6.

These definitions make most sense for complex systems near the spectral corner $P$ in Fig. 1. Emergent wonders near the corner $Q$ may play special roles in broad markets, as we can recognize them in computer hardware, inside smartphone screens. But the meaning of cause delegation within their internal homogeneous "markets" requires further interpretation, as I briefly discuss in the next section.

Delegated causation ought to play important roles in realistic complex systems, and it should be included in the modeling. Its radical openness (Chu 2011) discourages modeling of complex phenomena by single dynamical systems. On the other hand, delegated causation allows to explicate cybernetic links, tipping points, feedback loops. The following methodological steps of analyzing a single delegated interaction must be useful:

[M1] Identify the primed dynamical system in the interaction. Determine its sensitivity to perturbations, and possible reactions to perturbations.

[M2] Identify the perturbing influences; describe their mechanism.

[M3] Describe the context, the broad market of the interaction.

This methodology is illustrated in Sect. 5 by series of biological examples. The factor [M2] can be identified as an interventional cause. I view [M1] and [M2] as a dual pair of delegated and interventional causations. In the common language, "delegation" describes plausibly the cases when $[M I]$ is strong, while "intervention" describes the cases when [M2] dominates. I use the language of delegation in the abstract and general sense of the causal factor $[M 1]$ in any interaction.

Layers of delegated causality signify systems with great dynamical depth (Deacon and Koutroufinis 2014). Measures of Kolmogorovian sophistication (Mota et al. 2013) are promising for quantifying system complexity. My perspective recommends perturbative analysis of dynamical systems and complexity measures, because significance of primed systems lies in their interactive potential. 
Table 1 Biological examples of delegation-intervention analysis, as outlined in Sect. 3

\begin{tabular}{|c|c|c|}
\hline$[M 1]$ & {$[M 2]$} & {$[M 3]$} \\
\hline Cell & Cardiovascular system & Supply of oxygen, nutrients \\
\hline Cardiovascular system & Heart & Blood circulation \\
\hline Tissues, organs & Endocrine system & Hormonal coordination \\
\hline Pathogenic infection & Immune system & Protection from diseases \\
\hline Host organism & Parasite & Parasitism \\
\hline Prey & Predator & Food chain \\
\hline Ecosystem & Invasive species & Ecological disruption \\
\hline Habitat & Niche construction & Adaptive alteration of the environment \\
\hline Species population & Mountainous topography & Geographic speciation \\
\hline Heritable variation & Differential reproduction & Natural selection \\
\hline Gene pool & Sexual reproduction & Increased genetic variation \\
\hline Genetic drift & Punctuated equilibrium & Macro-evolution \\
\hline Chemical compounds & Enzyme & Catalyzed reaction \\
\hline Nucleic acids & Ribosome & Protein synthesis \\
\hline Allosteric enzymes & Inhibitory of activating metabolites & Regulation of metabolic pathways \\
\hline $\begin{array}{l}\text { Reactants with comple- } \\
\text { mentary sites }\end{array}$ & Non-covalent bonding & Versatile stereospecific discrimination \\
\hline Oligomeric proteins & Stereospecific bonding & Spontaneous self-assembly \\
\hline Stereospecificity & Chemical potential & Information amplification \\
\hline Fertilized egg & Genome & Ontogenic development \\
\hline Genome & Gene regulatory network & Morphogenesis \\
\hline Stem cells & Variable gene expression & Cell differentiation \\
\hline Germ layers & Cell sorting, EMT & Tissue separation \\
\hline
\end{tabular}

Delegated causality amounts to a significant case of Deacon's (2011) specific absence as a "pulling" causal force (see also Clayton and Davies 2006, p. 119). Causal roles of constrained absences, virtual demands, "pregnant" (Salthe 2012, section 9) opportunities merit good appreciation. For example, early stages of the British industrial revolution were much stimulated by specific needs of textile, iron, and mining industries (Deane 1979).

On the other hand, dynamical laws and initial conditions enjoy the respectful status of causes. But chaotic dynamics and causality delegation undermine that status. If an attractor, an equilibrium, or a self-organized state is reached regardless of initial conditions, what is exactly a cause?

\section{Physical Reductionism}

Openness of delegated causality conforms well with Pearl's (2000) empirical analysis of causation in terms of interventions and counterfactuals. Interventions are "actions as external entities, originating from outside our theory, not as 
a mode of behavior within the theory" (Pearl 1999). Causative interventions on primed dynamical systems (and possible malfunctions as reverse interventions) must be pivotal features of complex systems.

My first weighty thesis is this: delegated causation offers a conceptual mechanism how micro-scale dynamics results in empirical causation from macro-level agencies in terms of Pearl's (2000) causal calculus and Hoel's (2017) causal emergence. Here is one rationale formulated in the economic terminology: complex events are better temporally correlated with appearance of supply rather than with an onset of demand, commonly. A row of falling dominos can be interpreted as a prototypical example. It would be instructive to relate sensitivities of microlevel dynamics and effective information (Hoel 2017) measures in a compelling example of a "smoothly" emergent phenomenon.

As a mechanism of downward causation, delegated causality often entails environmental influence. Other proposed mechanism of downward causation via environmental interaction is practopoietic cycle (Nicolić 2015, section 2.6).

My second weighty thesis refers to Gödel's (1931) incompleteness theorem. Delegated causality has a self-contradictory flavor of a Gödelian paradox (Humphries 1979) in the causality language. This messes up basic principles for physicalism (Kim 2005), and Kim's (1998) argument against non-reductive physicalism. In particular, the causal closure principle says that if a physical event has a cause, it has a physical cause (Clayton and Davies 2006, p. 199), and the exclusion principle states that no single event can have two independent sufficient causes (Kim 2005, p. 41). Kim's conclusion is that non-physical (say, mental) events can have no causal power. In contrast, delegated causality provokes causal, informational contribution from external agents or from an emerging organization, even if delegation is not ideal. Sufficiency of physical causation is debatable then. Delegated causality clarifies inevitability of causal parity (Weber 2018) and levels of explanation. It furnishes hierarchical dynamics, which in turn reinvigorates Aristotle's four categories of material, formal, efficient and final causes (Coffman 2011; Salthe 2012, section 9).

Incidentally, Popper (1974) invoked Gödel's theorem in his argument against reductionism. By a similar reference to Gödel's incompleteness, Rosen (1991) repudiated theoretic formalization of life. Kim's epiphenomenal implications have been countered by interventional (Shapiro and Sober 2007) and counterfactual (List and Menzies 2009) argumentation.

Causality and reduction in emergent phenomena are customarily analyzed in terms of supervenience (Butterfield 2012; Stalnaker 1996; Clayton and Davies 2006, pp. 189-243): the principle that entities with the same micro-level properties will have the same macro-level properties. A supervenience is often defined by a coarse-graining map from physical micro-states to emergent macro-level states.

Delegated causality amounts to engaging external information, possibly entailing an externalist (Clark and Chalmers 1999; Menary 2010) propensity to expand the supervenience base of micro-states beyond memorization, representation. This propensity can be quickly consummated in complex systems near the corner $P$, making a supervenience analysis doubtful. For example, an animal may habitually follow certain external clues, peer group behavior or "expert" guidance. Or the 
neuro-physiological basis of its behavior might be "eagerly" changing in live action. These are examples of situated, embodied cognition (Wilson 2002).

Human consciousness and free will are the most prominent emergent phenomena. Without more ado, they could be viewed as pinnacles of delegated causation in the known cosmos. From a utilitarian perspective, consciousness is a cognitivebehavioral characteristic that is able to intervene on (sometimes particularly quiet) emotional, somatic drivers.

Can emergent systems near the corner $Q$ in Fig. 1 be interpreted as "eagerly" seeking outside influence, even if the outside is presumably negligible? In a sense, phase transitions delegate causality to dust particles, matter irregularities. Most dramatically, we can consider the whole Universe with no outside in principle. Can we then speculate that a collective behavior of the system is seeking to externalize its statistical parameters, thermodynamic "forces" (Onsager 1931), thereby meeting Mach's principle (Jannes and Volovik 2015), renormalization group dynamics (Batterman 2000; Mainwood 2006, Ch. 3), Heisenberg's indeterminacy, or an observer at the "boundary"? Can dynamic novelty be a valid extension of a supervenience basis? Does emergence itself reflect primordial ways of conceding causality? At least, these speculations could be simulated by a chaotic, fractal or hardly computable topology of the supervenience map, while the macro-dynamics would be described by smooth functions. The consideration of emergence as delegated causality is supported by the recently established correspondence between the renormalization group in theoretical physics and the deep learning approach in artificial intelligence (Wolchover 2014; Mehta and Schwab 2014); I elaborate this in Sect. 7.

The above questions ought to be addressed by theories of everything (Hawking 2005). Delegated causality gives an apparent taste of physical implications of Gödel's incompleteness theorem (Jaki 1966; Dyson 2004; Hawking 2002). It may even turn out to be a reformulation of Gödel's incompleteness in causal terms.

The notion of delegated causality enhances rather than renounces the reductionist paradigm by defining the causal role of critical, "edge of chaos" systems. Possibilities of extravagant dynamics are wholly controlled by micro-level arrangements. But dynamical actualization is contingent to particular instabilities or input from the environment.

\section{Biological Causality}

Biology is a great ground for testing explanatory power of delegated causality. We can expect lots of elaborate causative interventions, provocations.

Mayr's (1961) influential article distinguishes proximate (mainly physiological) and ultimate (mainly evolutionary) causes of biological phenomena. Contrary to the reductionist template, the relatively more "teleological" level of explanation by natural selection and adaptation is considered more fundamental in the conventional (neo-Darwinian) Modern Synthesis. Physiological development is guided by the genetic code, which in turn is pressured by natural selection. By a rigid interpretation of Modern Synthesis, biological functionality and organisms can be fully understood only from the evolutionary perspective, while comprehension of ontogenic development is principally 
unnecessary for that. This reduction of biological causes to statistical phenotype selection, genetic adaptation and drift could be a deep reason of steady critique of the Modern Synthesis (Laland et al. 2014; Welch 2017; Gould and Lewontin 1978; Pigliucci and Muller 2010; Vijver et al. 1998).

Laland et al. (2011, 2013) suggest that Mayr's proximate-ultimate dichotomy, although still vital, hinders a proper integration of evolution and development, recognition of multiple sources of evolutionary novelty. They advocate an intimate relation between developmental and evolutionary processes, with the former able to influence evolutionary change through phenotypic plasticity, developmental bias, epigenetic inheritance, behavioral changes, and ecological interactions such as niche construction. This is a good list to test scientific productivity of the delegated causality notion. Genes are masters of causal intervention in the biological world, enjoying vast biochemical infrastructure. But they themselves may be open to interventions. Feedback from developmental and ecological conditions would be a powerful source of adaptation, with diversified agencies and information forms as inevitable effects.

The methodology [M1]-[M3] in Sect. 3 of explicating delegated causation is helpful to highlight interventional forces [M2] and signification [M3] of interactions. This is illustrated in Table 1 by several physiological, ecological, evolutionary, biochemical (Monod 1972), and developmental (Fagotto 2014; Nieto et al. 2016) examples. In many cases, the dual force of intervention dominates. But the central role of genes is compellingly a cybernetic hub of delegation, as I recount again in the middle of Sect. 7. In the biochemical context, the columns [M1], [M2] delineate Rosen's (1991) rendition of Aristotle's material and efficient causes, respectively. Systemic closure of efficient causes is underscored by theories of biological autonomy (Moreno and Mossio 2015; Maturana and Varela 1980). In the context of causal stability and specificity (Calcott 2017; Woodward 2010), the factor [M1] tends to provide specificity, while [M2] furnishes stability and permissiveness. The analysis [M1]-[M3] must offer more clarity than the proposal in (Laland et al. 2011, 2013) to employ a terminology of reciprocal causation. The polarity between Mayr's proximate and ultimate causes should rather stay.

Other biological disciplines where explicit analysis of delegated causation ought to be useful are microbiology, symbiosis (Margulis and Fester 1991), communication (d'Ettorre and Hughes 2008). The contentious subjects of group selection (Wilson and Sober 1994), multilevel selection (Okasha 2006), evolvability (Crutchfield and Schuster 2003), cooperation (Nowak 2006), altruism (Sober and Wilson 1988), longer term adaptation might be greatly altered by the perspective of delegated causation as well. The criticized theory of Wynne-Edwards (1962) of territorial and hierarchical organizations in various species regulating population growth becomes more plausible, as game-theoretic explanations (Dawkins 1976, Ch. 7) turn into proximate causes relative to the "ultimate" adequacy between population size and resources. Mayr (2004, Ch. 8) acknowledges selection of cohesive social groups because their fitness values can be disproportionately larger than the mean values of individual fitness. This is reminiscent to the emergence principle that the whole is greater than the sum of its parts. 


\section{Yin and Yang}

Conceptions resonating with delegated causality can be found in Chinese philosophy. Provocation of some experiential apprehension from readers looks sensible or frankly unavoidable in this presentation. That being the case, this section could be excused for being a little rhetorical. Certain cultural, social parallels may be promptly triggered. Carefully evaluative readers are encouraged to contain social, emotional charges and judgements.

The ancient Chinese concepts of Yin and Yang are customarily evoked to affirm complementarity of opposing, interdependent forces. It is less widely known that Yin and Yang are defined (Oxford 2010) as two concrete complementary principles. The complementary harmony is better underscored by Taoism (Capra 1975), while the particular duality is more emphasized by Confucianism (Rosenlee 2007). Recently, the Yin-Yang polarity has been interestingly related to holistic causality (Chung 2016), epistemology (Zhang and Zhang 2007; Benetatou 2016), transformational change (Klein and Wong 2012; Li et al. 2012), and even microbiology (Zhang 2014), molecular biology (Gordon et al. 2006).

One of the defining complementarities is that Yin is an abstraction of passivity, inertness, while Yang is the active, generative principle. This particular duality captures the contrast between mechanical dynamical systems and emergent phenomena very well. A primed dynamical system of Definition 1 would be a passively reactive Yin, while any effective influence in Definition 3 would be Yang. It seems fittingly convenient to adopt this language.

Paraphrasing an earlier statement, dynamic realization of Yang is beside the main point. Yang is the novelty, emergence beyond Yin's territory. Relative to underlying Yin dynamics, Yang is a hero (Campbell 1968), a master, an artful trickster. Yang is the magic of actualizing synergetic possibilities. Yang "opposes" entropy increase by causative leadership, blocking unwelcome occurrences, forcing a decisive turn of action, claiming the language of communication.

It is not necessary to assume supernatural causes to explain Yang manifestations. Yin's ready anticipation of external perturbation and yielding to self-precipitated pressures are pulling causative forces already. Yang is defined by this anticipatory perception of Yin. We may refer to a finely triggered Yin's incipient reaction as Yin's satisfaction. In some cases, this satisfaction may be prompted straightforwardly; in other cases it may be an uncertain, rare event. Both Yin and Yang of a particular interaction may evolve to sophisticated cybernetic levels, meeting criteria of a broad market.

With many Yin agents available as amenable resources, Yang competition to employ them emerges. Or who harnesses whom? Attribution of selection powers is relative in multifaceted interactions of Yin and Yang. There is a certain mutual inclusion of Yin and Yang, symbolized by the taijitu sign: 


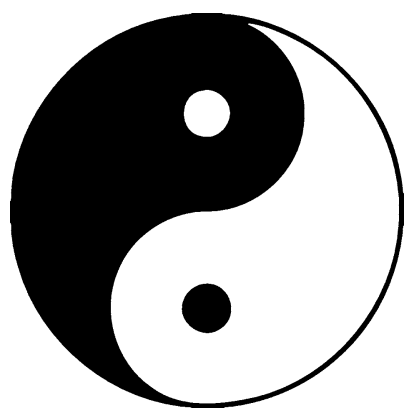

For example, a perceptual mechanism is Yin primed to be affected by the environment. But Yang should have perceptual capabilities to recognize peer Yin's dynamic demand and address it.

The simplest mechanism of Yang (as external dynamics) is randomness. This means, Yin allows chance to direct its dynamics. For example, divination rituals were common in ancient human societies. In China of the Shang dynasty (circa $1600 \mathrm{BC}-1046 \mathrm{BC}$ ), oracle bones of ox or turtle were prominently used (Keightley 1978). Other simple mechanism for Yang is competition. That is, Yin sets up a contest who best performs or fakes a particular demand. Another manifestation of Yang is information. Generally, Yang can be identified in processes that are called "teleological" now and then. It is instructive to inspect Mayr's (2004, Ch. 3) classification of five teleologies: "four of the five phenomena traditionally called teleological can be completely explained by science, while the fifth one, cosmic teleology, does not exist." The similar list of Ellis (2012; 2016, Ch. 4) of five downward causations is definitely germane as well.

\section{An Integrated View}

The two weighty theses in Sect. 4 relate delegated causality to emergence and Gödel's incompleteness theorem. Emergence and Gödel's theorem are brought together in the literature at times (Requardt 1991). For example, Jorgensen and Svirezhev (2004, p. 8) write : "In accordance with Gödel's Theorem, the properties of order and emergence cannot be observed and acknowledged from within the system, but only by an outside observer." It could be meaningful to consider emergent phenomena and selection modes as physical, biological, or socionomic (Prechter 2003) manifestations of Gödel's incompleteness. Monod's (1972, Ch. IV) concept of gratuity -i.e., independence between chemical qualities and function of biochemical processes_can be similarly related to Gödel's theorem as well.

Delegated causality facilitates hierarchical dynamics and defines Nature's "joints" (Salthe 2012, section 4) along which dynamical levels are fused. Higher levels impose boundary conditions, constrains, selection regimes on dynamics of lower levels (Juarrero 1999). This downward causation is enabled by critical, primed organization of the lower levels. Intermediate "sub-wholes" in a dynamical 
hierarchy are Koestler's (1978) holons-i.e., stable, integrated, largely autonomous, yet interactive entities. They are both primed dynamical systems and interventional forces, both consumers of energy and local sources of order. The constrains of a dynamical level define distinct dynamics, bias, functionality, and a "behavior code" of the holons.

Recently (Mehta and Schwab 2014; Wolchover 2014), an equivalence between the renormalization technique in condensed matter physics and the deep learning approach in artificial intelligence was established. This reinforces the interpretation that micro-dynamics of a phase transition [or a dissipative system such as Bénard's cells (Goldhirsch and Procaccia 1981; Swenson 1997, pp. 22-25)] is organizing itself to "explore" and adjust to macro-boundaries. The scale-free dynamics extends mean free-path distances and relaxation times of particle interactions by orders of magnitude, until limiting macro-dimensions are eventually met. Causality delegation becomes a paraphrase of this "deep learning" of macro-dimensions.

This enriched metaphorical context echoes the Santiago school view of living systems as cognitive (Maturana and Varela 1980), sense making (Thompson 2007) systems, and Heylighen's (2011) view of evolution and self-organization as cognitive processes. The action-centered ontology (Heylighen 2011) assigns intentional stance (Dennett 1987) to increasingly adaptive agents, and (in essence) recognizes interventions as basic constituents of reality. But the passive, incomplete kind of delegated causality should be recognized as well. Deacon's (2011) cryptic notion of ententionality is relatable here, if it characterizes being organized for some functioning. Elements of anticipation relate primed dynamical systems, deep learning, and enactive (Varela et al. 1991, Ch. 8) cognition. The focus of anticipation defines the cognition aim or the significance, aboutness (Yablo 2014) of expected dynamical triggers.

Primed dynamical systems and delegated causality ought to be discerned in all phenomena and entities that are considered emergent or self-organizing. For example, a living cell is predominantly a product of developmental processes that delegate their coordination to genes. Biochemical reactions in the cytoplasm are orchestrated by genes in the form of nucleic acids, but epigenetic switching, energy input from mitochondria, and nutrient flow determine the mode of metabolism. Arrangements of tissues and organs are coordinated by genes again, but the behavior and fate of organic "vehicles" (Dawkins 1976, section 12) are delegated to the nervous system, sociality, tribal customs, or eventually to democratic politics. Natural, symbiotic, artificial, and cultural selections blend into a rather continuous spectrum of efficient causes.

Intuition on delegated causality can be further enhanced by reflecting on many regarded modes of economic causality (Hoover 2001; Morck and Yeung 2011; Varian 2016; Joffe 2017). Furthermore, it is worth to reflect on causality of avalanches in self-organized critical systems (Bak 1996; Watkins et al. 2015), where (in theory) only a scale-free statistical distribution has a predictive power. Scale-free dynamics in heterogeneous systems near the corner $P$ in Fig. 1 can be self-reinforced by a few persistent motives of adaptation throughout the scale expanse.

The Chinese concepts of Yin and Yang describe dynamical discontinuities fittingly. The interaction between Yang's constraints and Yin's demand or 
satisfaction should define a statistical partition for a relevant entropy tally, and the semantics of what is caused by delegation. Yang's contingency suggests that universal principles of self-organization or non-equilibrium thermodynamics [such as speculated laws of maximal entropy production (Swenson 1997)] would rather describe potentialities.

Overwhelming interventions, catastrophes, dynamical collapses, black swans (Taleb 2007) fit the presented context of delegated causality as Yang forces. Resignation to them would not be called "delegation" in the common language. On the other hand, ignoring predictably unsustainable trends (even if the timing and operation of a likely resolution is highly uncertain) amounts to delegation of responsibilities for consequences. For example, human conscious effort to address a climate change (Zhang et al. 2011) is a potentially significant causal factor. Likelihood of a catastrophe indicates a primed dynamical system, to be influenced possibly by its constituents.

The perspective of Yin and Yang applies to the cultural discord between conservative and post-modernist (Foucault 1980) views in the United States. As the American academic critic Bloom (1987, p. 25) noted, the post-modernist "relativity of truth is not a theoretical insight but a moral postulate". Post-modernism can be viewed as celebration of Yin birthrights and subjective preferences, as well as denial of Yang authority. Firstly however, limitation of resources is not addressed operatively by the progressive optimism. That is left implicitly to social, political, or financial (Graeber 2011) hierarchies, be them patriarchal or not. Congruent resolution of oppression and sustaining social progress may continue to be historical challenges (Graeber 2011, p. 183), especially under a prolonged environmental stress. Secondly, Yang standards of leadership are yet appreciated by the progressive electorate. This is evident from the 2016 US presidential election (Reynolds 2017), where Hillary Clinton did not fully motivate her expected voters.

\section{In Conclusion}

Common experience, biology (Mayr 2004), empirical causality (Pearl 2000), information measures (Hoel 2017; Tononi and Sporns 2003) tell that downward causation apparently exist. The interpretation of the ancient Chinese concept of Yin as a primed dynamical system intimates that downward causation does exist in a very strong, virtually mechanical sense. Instead of having "higher scales wrest the controls from lower scales" (Wolchover 2017), the lower scales can be organized to operatively concede a good deal of causality to some higher scales. This possibility shifts the reductionistic paradigm in a novel way (Kuhn 1970). The duality of delegated and interventional causations is subtly eminent in Yin-Yang philosophy. Letting things go their way for a matched balance is a part of this duality.

Co-evolution of agencies with expanding capabilities to provoke, perceive, impose causal relations can lead to understandably tremendous consequences. Conspicuously complex natural systems build up on interactions of delegated causality. This must be it. 
Acknowledgements Open access funding provided by Max Planck Society. This article is influenced by informed experience of personal development since 2012. The understanding of Yin and Yang is inspired by works of David Deida, Adam Gilad, David Shade. The emphasis on causality sank in while listening to Jason Capital, Bobby Rio. For an introduction to externalist, interventional, mythological perspectives, thanks to Joseph Riggio. Constructive comments from Ari Belenkiy, Marianne Benetatou, James Read, Stanley Salthe, Susumu Tanabe, Alexander Tokmakov, and fruitful conversations with Yang-Hui He, Minxin Huang, Sanjaye Ramgoolam, George Shabat are much appreciated.

Open Access This article is distributed under the terms of the Creative Commons Attribution 4.0 International License (http://creativecommons.org/licenses/by/4.0/), which permits unrestricted use, distribution, and reproduction in any medium, provided you give appropriate credit to the original author(s) and the source, provide a link to the Creative Commons license, and indicate if changes were made.

\section{References}

Anderson PW (1972) More is different: Broken symmetry and the nature of the hierarchical structure of science. Science 177:393-396

Ariew A, Cummins R, Perlman M (eds) (2002) Functions. Oxford University Press, Oxford

Ashby WR (1962) Principles of the self-organizing system. In: von Foerster H, Zopf GW (eds) Principles of Self-organization: transactions of the University of Illinois symposium. Pergamon Press, Oxford, pp 255-278

Bak P (1996) How nature works: the science of self-organized criticality. Copernicus, New York

Batterman RW (2000) Multiple realizability and universality. Br J Philos Sci 51:115-145

Benetatou M (2016) Aristotelian organicism, Yin Yang theory and our representation of reality. Biocosmology - Neo-Aristotelism 6:41-49

Bloom A (1987) The closing of the American mind. Simon \& Schuster, New York City

Brochini L, de Andrade Costa, A, Abadi M, Roque AC, Stolfi J, Kinouchi O (2016) Phase transitions and self-organized criticality in networks of stochastic spiking neurons. Sci Rep. https://doi. org/10.1038/srep35831

Butterfield J (2012) Laws, causation and dynamics at different levels. Interface Focus 2:101-114

Calcott B (2017) Causal specificity and the instructive-permissive distinction. Biol Philos 32:481-505

Campbell J (1968) The hero with a thousand faces. Princeton University Press, Princeton

Capra F (1975) The Tao of physics. Shambhala Publications, Boulder

Capra F, Luisi PL (2014) The systems view of life. Cambridge University Press, Cambridge

Chu D (2011) Complexity: against systems. Theory Biosci 130:229-245

Chung D (2016) Can reference be naturalized?-Notes toward an integrational causality. Philos Study 6:289-304

Clark A, Chalmers D (1999) The extended mind. Analysis 58:10-23

Clayton P, Davies P (eds) (2006) The re-emergence of emergence. Oxford University Press, Oxford

Coffman JA (2011) On causality in nonlinear complex systems: the developmentalist perspective. In: Hooker C (ed) Philosophy of complex systems. North Holland, Amsterdam, pp 287-309

Corning PA (2005) Holistic Darwinism: synergy, cybernetics, and the bioeconomics of evolution. University of Chicago Press, Chicago

Crutchfield JP, Schuster P (eds) (2003) Evolutionary dynamics: exploring the interplay of selection, accident, neutrality, and function. Oxford University Press, Oxford

Dawkins R (1976) The selfish gene. Oxford University Press, Oxford

de Wolf T, Holvoet T (2005) Emergence versus self-organisation: different concepts but promising when combined. In: Engineering self-organising systems: methodologies and applications, volume 3464 of LNAI. Springer, Berlin, pp 1-15

Deacon T (2011) Incomplete nature: how mind emerged from matter. W. W. Norton \& Company, New York City

Deacon T, Koutroufinis S (2014) Complexity and dynamical depth. Information 5:404-423

Deane PM (1979) The first industrial revolution. Cambridge University Press, Cambridge

Dennett DC (1987) The intentional stance. MIT Press, Cambridge 
Depew D, Weber B (1999) Self-organizing systems. In: Wilson RA, Keil FC (eds) The MIT encyclopedia of the cognitive sciences. MIT Press, Cambridge, pp 737-739

d'Ettorre P, Hughes DP (eds) (2008) Sociobiology of communication. Oxford University Press, Oxford

Dyson FJ (2004) The NY Reviews of Books. http://www.nybooks.com/articles/2004/05/13/the-world-ona-string/

Ellis G (2012) Top-down causation and emergence: some comments on mechanisms. Interface Focus 2:126-140

Ellis G (2016) How can physics underlie the mind? Top-down causation in the human context. Springer, Berlin

England JL (2013) Statistical physics of self-replication. J Chem Phys. https://doi.org/10.1063/1.4818538

Fagotto F (2014) The cellular basis of tissue separation. Development 141:3303-3318

Foucault M (1980) Power/lknowledge: selected interviews and other writings 1972-1977. Pantheon Books, New York City

Gödel K (1931) Über formal unentscheidbare Sätze der Principia Mathematica und verwandter Systeme I. Monat Math Phys 38:173-198

Goldhirsch I, Procaccia I (1981) Threshold behavior at the onset of the Rayleigh-Bénard instability. Phys Rev A 24:580-597

Gordon S, Akopyan G, Garban H, Bonavida B (2006) Transcription factor YY1: structure, function, and therapeutic implications in cancer biology. Oncogene 25:1125-1142

Gould SJ, Lewontin R (1978) The spandrels of San Marco and the Panglossian paradigm: a critique of the adaptationist programme. Proc R Soc Lond 205:581-598

Graeber D (2011) Debt: the first 5000 years. Melville House, Brooklyn

Hackley Ch, Brown S, Hackley RA (2012) The X-Factor enigma: Simon Cowell and the marketization of existential liminality. Mark Theory 12:451-469

Hawking S (2002) Gödel and the end of physics. Caltech lecture. http://www.damtp.cam.ac.uk/events/ strings02/dirac/hawking/

Hawking S (2005) The theory of everything: the origin and fate of the universe. Phoenix Books, Rutland

Heylighen F (2000) Foundations and methodology of an evolutionary world view: a review of the Principia Cybernetica project. Found Sci 5:457-490

Heylighen, F (2011) Self-organization of complex, intelligent systems: an action ontology for transdisciplinary integration. Integral Rev (in press)

Heylighen F, Cilliers P, Gershenson C (2007) Complexity and philosophy. In: Bogg J, Geyer R (eds) Complexity, science and society. Radcliffe Publishing, London, pp 117-134

Hoel EP (2017) When the map is better than the territory. Entropy. https://doi.org/10.3390/e19050188

Holland JA (1995) Hidden order: how adaptation builds complexity. Addison-Wesley, Boston

Hoover KD (2001) Causality in macroeconomics. Cambridge University Press, Cambridge

Horgan J (1995) From complexity to perplexity. Sci Am 272:104-109

Humphries J (1979) Gödel's proof and the liar paradox. N D J Form Log 20:535-544

Jaki SL (1966) The relevance of physics. University of Chicago Press, Chicago

Jannes G, Volovik GE (2015) Emergent physics on Mach's principle and the rotating vacuum. JETP Lett 102:73-79

Joffe M (2017) Causal theories, models and evidence in economics - some reflections from the natural sciences. Cogent Econ Finance. https://doi.org/10.1080/23322039.2017.1280983

Johansen A, Sornette D (2001) Finite-time singularity in the dynamics of the world population, economic and financial indices. Physica A 194:465-502

Jorgensen SE, Svirezhev YM (2004) Towards a thermodynamic theory for ecological systems. Elsevier, Amsterdam

Juarrero A (1999) Dynamics in action: intentional behavior as a complex system. MIT Press, Cambridge

Kauffman SA (1993) The origins of order: self-organization and selection in evolution. Oxford University Press, Oxford

Keightley DN (1978) Sources of Shang history: the oracle-bone inscriptions of bronze age China. University of California Press, Berkeley

Kim J (1998) Mind in a physical world. MIT Press, Cambridge

Kim J (2005) Physicalism, or something near enough. Princeton University Press, Princeton

Klein L, Wong T (2012) The Yin and Yang of change: systemic efficacy in change management. In: Prastacos GP, Wang F, Soderquist KE (eds) Leadership through the classics: learning management and leadership from ancient East and West philosophy. Springer, Berlin, pp 475-486

Koestler A (1978) Janus: a summing up. Vintage Books, New York City 
Kondepudi D, Kay B, Dixon J (2015) End-directed evolution and the emergence of energy-seeking behavior in a complex system. Phys Rev E. https://doi.org/10.1103/PhysRevE.91.050902

Kuhn TS (1970) The structure of scientific revolutions. University of Chicago Press, Chicago

Laland KN, Sterelny K, Odling-Smee FJ, Hoppitt W, Uller T (2011) Cause and effect in biology revisited: is Mayr's proximate-ultimate dichotomy still useful? Science 334:1512-1516

Laland KN, Odling-Smee J, Hoppitt W, Uller T (2013) More on how and why: cause and effect in biology revisited. Biol Philos 28:719-745

Langton ChG (1990) Computation at the edge of chaos: phase transitions and emergent computation. Physica D 42:12-37

Laland K, Uller T, Feldman M, Sterelny K, Muller GB, Moczek A, Jablonka E, Odling-Smee J, Wray GA, Hoekstra HE, Futuyma DJ, Lenski RE, Mackay TF, Schluter D, Strassmann JE (2014) Does evolutionary theory need a rethink? Nature 514:161-164

Lerner VS (2007) Systems science, information systems theory, and informational macrodynamics: review. Kybernetes 36:192-224

Li J, Leung A, Young M, Xin Y, Cai Zh, Huang J (2012) A Yin/Yang perspective on the 2008 global financial crisis. Br J Manag 23:119-125

List C, Menzies P (2009) Non-reductive physicalism and the limits of the exclusion principle. J Philos 106:475-502

Mainwood P (2006) Is more different? Emergent properties in physics. Ph.D. thesis, University of Oxford

Margulis L, Fester R (eds) (1991) Symbiosis as a source of evolutionary innovation. MIT Press, Cambridge

Maturana J, Varela F (1980) Autopoiesis and cognition: the realization of the living. Reidel, Kufstein

Mayr E (1961) Cause and effect in biology. Science 134:1501-1506

Mayr E (2004) What makes biology unique?. Cambridge University Press, Cambridge

Mehta P, Schwab DJ (2014) An exact mapping between the variational renormalization group and deep learning. https://arxiv.org/abs/1410.3831

Menary R (ed) (2010) The extended mind. MIT Press, Cambridge

Miller JH, Page SE (2007) Complex adaptive systems: an introduction to computational models of social life. Princeton University Press, Princeton

Monod J (1972) Chance and necessity. Vintage Books, New York City

Moon J-Y, LaRock E (2017) On emergence from the perspective of physical science. http://arxiv.org/ abs/1705.11075

Morck R, Yeung B (2011) Economics, history, and causation. Bus Hist Rev 85:39-63

Moreno A, Mossio M (2015) Biological autonomy: a philosophical and theoretical enquiry. Springer, Berlin

Mota F, Aaronson S, Antunes LFC, Souto A (2013) Sophistication as randomness deficiency. In: Jurgensen H, Reis R (eds) DCFS 2013. Springer, Berlin, pp 172-181

Murphy MP, O’Neil LAJ (eds) (1995) What is life? The next fifty years. Cambridge University Press, Cambridge

Nicolić D (2015) Practopoiesis: or how life fosters a mind. J Theor Biol 373:40-61

Nieto MA, Huang RY, Jackson RA, Thiery JP (2016) EMT: 2016. Cell 166:21-45

Nowak MA (2006) Five rules for the evolution of cooperation. Science 314:1560-1563

Okasha S (2006) Evolution and the levels of selection. Clarendon Press, Oxford

Onsager L (1931) Reciprocal relations in irreversible processes, I. Phys Rev 37:405-426

Oxford (2010) Oxford English Dictionary, 3rd edn. Oxford University Press, Oxford

Pearl J (1999) Reasoning with cause and effect. Research Excellence Award Lecture, 1999. International Joint Conference in Artifical Intelligence. http://bayes.cs.ucla.edu/IJCAI99/. Accessed July 2017

Pearl J (2000) Causality: models, reasoning, and inference. Cambridge University Press, Cambridge

Pigliucci M, Muller GB (eds) (2010) Evolution, the extended synthesis. MIT Press, Cambridge

Popkin G (2016) The physics of life. Nature 529:16-18

Popper K (1974) Scientific reduction and the essential incompleteness of all science. In: Ayala FJ, Dobzhansky T (eds) Studies in the philosophy of biology. University of California Press, Berkeley, pp 259-284

Prechter RP (2003) Socionomics: the science of history and social prediction. New Classics Library, Gainesville

Prigogine I, Nicolis G (1977) Self-organization in non-equilibrium systems. Wiley, Hoboken

Requardt M (1991) Gödel, Turing, Chaitin and the question of emergence as a meta-principle of modern physics. Some arguments against reductionism. World Futures 32:185-195 
Reynolds E (2017) What if Donald Trump and Hillary Clinton had swapped genders? News story (online), February 28 2017. NY University

Rosen R (1991) Life itself: a comprehensive inquiry into nature, origin, and fabrication of life. Columbia University Press, New York City

Rosenlee L-H (2007) Confucianism and women: a philosophical interpretation. SUNY Press, Albany

Salthe SN (1993) Development and evolution: complexity and change in biology. MIT Press, Cambridge

Salthe SN (2012) Hierarchical structures. Axiomathes 12:355-383

Schrödinger E (1944) What is life? The physical aspect of the living cell. Cambridge University Press, Cambridge

Shapiro L, Sober E (2007) Epiphenomenalism - the do's and the don'ts. In: Machamer P, Wolters G (eds) Thinking about causes. University of Pittsburgh Press, Pittsburgh, pp 235-264

Simon HA (1962) The architecture of complexity. Proc Am Philos Soc 106:467-482

Sober E, Wilson DS (1988) Unto others: the evolution and psychology of unselfish behavior. Harvard University Press, Cambridge

Stalnaker R (1996) Varieties of supervenience. Philos Perspect 10:221-241

Swenson R (1997) Autocatakinetics, evolution, and the law of maximum entropy production: a principled foundation towards the study of human ecology. Adv Hum Ecol 6:1-47

Taleb NN (2007) The Black Swan: the impact of the highly improbable. Random House, New York City

Thompson E (2007) Mind in life: biology, phenomenology, and the sciences of mind. Harvard University Press, Cambridge

Tononi G, Sporns O (2003) Measuring information integration. BMC Neurosci. https://doi. org/10.1186/1471-2202-4-31

Varela FJ, Thompson E, Rosch E (1991) The embodied mind: cognitive science and human experience. MIT Press, Cambridge

Varian HR (2016) Causal inference in economics and marketing. PNAS 113:7310-7315

Vijver G, Salthe SN, Delpos M (eds) (1998) Evolutionary Systems: biological and epistemological perspectives on selection and self-organization. Springer, Berlin

von Bertalanffy L (1968) General system theory. Braziller, New York City

Waldrop MM (1993) Complexity: the emerging science at the edge of order and chaos. Simon and Schuster, New York City

Watkins NW, Pruessner G, Chapman SC, Crosby NB, Jensen HJ (2015) 25 years of self-organized criticality: concepts and controversies. Space Sci Rev. https://doi.org/10.1007/s11214-015-0155-X

Weber M (2018) Causal selection versus causal parity in biology: Relevant counterfactuals and biologically normal interventions. In Waters CK, Woodward J (eds) Philosophical perspectives on causal reasoning in biology, volume XXI of Minnesota studies in philosophy of science

Welch JJ (2017) What's wrong with evolutionary biology? Biol Philos 32:263-279

West G (2017) Scale: the universal laws of growth, innovation, sustainability, and the pace of life in organisms, cities, economies, and companies. Penguin Press, London

Wilson DS, Sober E (1994) Reintroducing group selection to the human behavioral sciences. Behav Brain Sci 17:585-654

Wilson M (2002) Six views of embodied cognition. Psychon Bull Rev 9:625-636

Wolchover N (2014) A common logic to seeing cats and cosmos. Quanta Mag (online). https://www. quantamagazine.org/deep-learning-relies-on-renormalization-physicists-find-20141204/

Wolchover N (2017) A theory of reality as more than the sum of its parts. Quanta Mag (online). https:// www.quantamagazine.org/a-theory-of-reality-as-more-than-the-sum-of-its-parts-20170601/

Wolfram S (2002) A new kind of science. Wolfram Media, Champaign

Woodward J (2010) Causation in biology: stability, specificity, and the choice of levels of explanation. Biol Philos 25:287-318

Wynne-Edwards VC (1962) Animal dispersion in relation to social behavior. Oliver \& Boyd, Edinburgh

Yablo S (2014) Aboutness. Princeton University Press, Princeton

Zhang DD, Lee HF, Wang C, Li B, Pei Q, Zhang J, An Y (2011) The causality analysis of climate change and large-scale human crisis. PNAS 108:17296-17301

Zhang Y (2014) Persisters, persistent infections and the Yin-Yang model. Emerg Microbes Infect. https:// doi.org/10.1038/emi.2014.3

Zhang H, Zhang Z (2007) The functional-analogical explanation in Chinese science and technology: a case study of the theory of Yin-Yang and five elements. In: Kacprzyk J, Magnani L, Li P (eds) Model-based reasoning in science, technology, and medicine, volume 64 of studies in computational intelligence. Springer, Berlin, pp 245-259 